\title{
IN THE CANOPY WITH TARDIGRADES, HERBIVORY AND WHEELCHAIRS: ENGAGING MOBILITY-LIMITED STUDENTS IN FIELD BIOLOGY
}

\author{
W.R. Miller, Ph.D. \\ Department of Biology,Baker University, Baldwin City, Kansas U.S.A. \\ M.D. Lowman, Ph.D. \\ California Academy of Sciences, San Francisco,California U.S.A. \\ E. McCord Jr., Ph.D. \\ Division of Natural Sciences,New College of Florida, Sarasota, \\ FloridaU.S.A. \\ R.L.Tripp \\ Department of Biology, University of Maine, Orono, Maine U.S.A.

\section{D.A. Glenny} \\ Department of Biology, Lebanon Valley College, Annville, Pennsylvania \\ U.S.A.

\section{A.T. Volpini} \\ Biochemistry Department and the Environmental Science Department, \\ University of Massachusetts-Amherst, Amherst, Massachusetts U.S.A.
}

\begin{abstract}
We conducted research to quantify tardigrade (water bear) density, diversity, and distribution in temperate forest canopies, and to promote opportunity for undergraduates with mobility limitations as field researchers. This ecology project was funded by the National Science Foundation (NSF) Research Experiences for Undergraduates (REU) program to explore canopy biodiversity and herbivory in a temperate deciduous forest, with a special focus on tardigrade fauna. The program confirmation that a wheelchair is not a limitation to field biology since canopy research involves vertical not horizontaltransects. Mobility-limited students with equal mental and visual capabilities ascended into the canopy, collected samples, used microscopes, identified new species, and wrote professional papers.
\end{abstract}

Keywords: Canopy, tardigrade, herbivory, disability, wheelchair 


\section{Introduction}

Miller, Lowman,and McCord (2013) boldly declared that canopy access and invertebrate ecology are disability-friendly arenas for rigorous scientific research, and we used that idea for our NSF (National Science Foundation of the United States) REU (Research Experiences for Undergraduates) proposal. Approximately $11 \%$ of US undergraduate students have physical limitations, but only $9 \%$ pursue studies in the life sciences and mathematics (NSF 2009), and an even smaller fraction of those students attempt studies in ecology or field biology (Teresa Mourad, Ecological Society, personal communication, 2012).

E.O. Wilson (2005) called forest canopies the "eighth continent of planet Earth" due to their complexity and enormous biodiversity. For decades, canopy exploration has concentrated on the exotic tropical rain forests, with few surveys in temperate regions (Preisser, Lowman, and Smith 1999; Shaw et al. 2006). This disparity of knowledge precludes answers to basic ecological questions about habitat selection, abundance, herbivory, diversity, vertical stratification, and evolution. This paucity of data provides the opportunities for undergraduate students to conduct primary, cuttingedge research into little known habitats and groups of invertebrates. Using protocols developed in the tropical forest canopies, undergraduate students can make discoveries in temperate forests (Bergelson et al. 1993).

Over the last two decades, ascent into the treetops has been facilitated by the development of safe single- and double-rope tree climbing techniques (SRT/DRT) (Lowman 1999, Haefke et al. 2013). This paradigm shift in accessibility has allowed canopy researchers to confirm that a large portion of global biodiversity inhabits the treetops (Lowman \& Rinker 2004). Our project combined the adventure of canopy exploration with the hunt for a little known, charismatic animal, the water bear or tardigrade (Miller et al 2013).

\section{Students with Disabilities as Field Biologists}

As equal opportunity educators, we, along with our institutions are dedicated to broadening opportunities for women, minorities, and persons with disabilities. Over many years, the authors have worked with students and colleagues with many disabilities, and recognized that a wheelchair does not preclude good science. Burgstahler (2009) wrote that any student who is given a research opportunity can observe, sample, and understand ecology. Students with disabilities have the same ability to think, question, hypothesize, analyze, and write as any other student. In the laboratory, students in or out of a wheelchair can use microscopes, analytical instruments, computers, and books to classify animals and interpret temporal and spatial data (Burgstahler 2009). "Yes, but how can a student in a 
wheelchair climb a tree?", is the first question asked of us, to which we point out that we employ technical hardware and ropes, so a person with average arm strength can climb into the canopy (Figure 1).

In Japan, the Treehab Program(treeclimbing.jp/Treehab.html) uses tree climbing in the therapeutic treatment of children with physical disabilities (Gathright et al. 2008). Although not ecological research, their project is a testimony to the idea that students with ambulatory disabilities need not be excluded from field biology or canopy exploration.

\section{Herbivory}

Herbivory in tropical rain forest canopies is lowest in sun leaves of the upper canopy. Insect herbivores prefer to eat young leaves more than mature ones (Lowman 1983, 1985, Lowman and Heatwole 1992, Lowman 2012). Further, insect herbivory has been shown to correlate to leaf toughness more significantly than to leaf chemistry (Lowman and Box 1983),however little is known about herbivory in temperate forest canopies.

\section{Tardigrades}

Tardigrades or water bears, are a little studied phylum of aquatic invertebrates living in the interstitial water that becomes trapped within the leaves of the mosses and thalli of lichens,and live as epiphytes on the trunks and branches of trees all over the world. Tardigrades exhibit cryptobiosis; they desiccate as their habitat dries and reconstitute when moisture returns (Miller 1997). In the dry state, tardigrade "tuns" can be picked up and carried by the winds. Thus, cryptobiotic tardigrades are rained into the canopies of the world, but must find acceptable habitat to survive (Miller 2004). Despite our knowledge of tardigrade physiology, we know almost nothing about their distribution and ecology (Ramazzotti and Maucci 1983, Kinchin 1994, Miller 1997, Mitchell et al. 2009). Miller, Gallardo, and Clark (2013) presented the first tardigrade vertical distributional pattern in a white pine tree in Kansas.

\section{Research}

This REU project exposed students to designing ecological field experiments, the development supportive laboratory work, and appropriate statistics to analyze data. We hypothesized uniformity or that there are no significant differences in the diversity and density of tardigrade populations at different levels on different substrates (tree species) (Miller et al. 2013). Our herbivory hypothesis was that there are no significant differences in herbivory at different levels throughout temperate forest canopies, similar to their tropical counterparts (Lowman 1985). 


\section{Materials \& Methods}

We worked in the transition zone between the tall grass prairie and the western edge of the great deciduous forest in eastern Kansas. Our research was based on simple vertical transects using double rope technique (Haefke et al. 2013), with sampling at standard levels: ground, low (3 m), mid $(7 \mathrm{~m})$, and high $(>10 \mathrm{~m})$. At each level in each tree (substrate), tardigrade habitats(moss and/or lichen) werecollected by scraping thehabitat into a paper bag. Each sample was processed in the lab and tardigrades mounted on slides (Miller 1997). The resulting data set from each substrate becomes statistically comparable to other tree species. The results at different levels are comparable to each other, as is the matrix of habitats (moss \& lichen) found within the canopy. Differences between forest types can be studied over years to develop a picture of temporal changes. Replicate leaf samples were similarly sampled along these vertical transects (see Lowman et al. 2012). In addition, each student was trained to use a scanning electron microscope to image their specimens and appreciate tardigrade morphology (Figure 2).

\section{Results}

As a team, mobility-limited or not, we climbed 117 trees (Figure 1) representing 20 different species, and collected 576 samples of moss \& lichen habitat from the four different levels. Over 4,256 tardigrades were extracted, slide mounted, imaged, and identified. Our preliminary results indicate the presence of 2 classes, 3 orders, 5 families, 8 genera, and16 species of tardigrade (Figure 2), six of which are new to Kansas, and four of which appear to be new to science. In addition, we collected 2,347 leaves in sets of 30 from almost each tree (some were out of reach), and measured leaf area and herbivory.

Preliminary results suggest distinct tardigrade stratification, with greater diversity and density in the upper canopy than the understory; association of specific tardigrade species with specific substrates anddifferent habitats (moss versus lichen); and evidence of differential site acceptability (Table 1). In addition, herbivory was significantly different between tree species (Figure 3).

Each student created a professional PowerPoint presentation for public audiences that were given in the Daily Planet Theater of the North Carolina Museum of Natural Sciences. Students have presented posters nationally at the Council of Undergraduate Research conference in Washington D.C., the Sigma Xi Undergraduate Research Symposium in North Carolina, and regionally at the Missouri and Kansas Academies of Science annual meetings. Numerous public outreach events have been 
orchestrated, including water bear scavenger hunts and public tree climbing workshops.

Recent research (Laurance et al. 2013) has indicated the sooner young scientists begin to publish, the greater their motivation and professional advancement later in their careers. As we write this, two of our students have already published peer reviewed papers (Haefke et al. 2013, Spiers et al. 2013) and five other manuscripts are in preparation. Co-author Tripp has recently published her experience in the canopy from her wheelchair in Ability Magazine (Tripp 2013).

\section{Discussion}

Our undergraduate canopy researchers have studied a major forest type, conducted research via DRT climbing, and used SEM to visualize their subjects. Students have identified new relationships among deciduous canopy trees and the epiphytes that grow upon them. They will have discovered and described new species, new habitats, and new characteristics in the canopy environment of the temperate forest. They have made poster and oral presentations, and many will have submitted a paper for publication. Our REU students are part of a growing research community of young scientists and canopy experts. All now have a core understanding of the achievements and challenges faced by colleagues with physical disabilities, and are well prepared for graduate school in ecological sciences.

The two students in this project with ambulatory disabilities have been full partners in this project, participating in every aspect. They climbed the same number of trees, climbed as high, and collected as many samples as the ambulatory students. They found as many tardigrades as the other students and measured as many leaves. They are writing as many papers. The circumstance that some participants were in wheelchairs presented no scientific problems and required only thoughtful logistics and planning. The fact that one project student was vegan was more of a challenge. During Open Tree Climbing Day at the North Carolina Museum of Natural Sciences, our students assisted more than a hundred people into the canopy at the Prairie Ridge Ecostation. Among those whom our students helped climb out of their wheelchairs included our own ADA consultant Pam Dorwarth. And recently, Dr. Gathright has contacted us about using water bears to introduce citizen science into his program in Japan.

This project demonstrates that students with ambulatory disabilities can conduct cutting edge research in the field, in the canopy, and in the laboratory, and communicate the results to both colleagues and the public. Thus we continue to declare that canopy access and invertebrate ecology are disability-friendly arenas for rigorous scientific research. 


\section{Acknowledgement}

This project was supported by NSFREUgrant (\#1156550) as a pilot program conducted at Baker University and the North Carolina Museum of Natural Sciences during the summer of 2013. We are grateful for access to field sites by the Kansas Biological Survey, the University of Kansas Field Station, the Overland Park Arboretum, and Baker University.

\section{References:}

Bergelson, J.M,, R.L. Kitching,M.D. Lowman and S. McIntyre. The biodiversity of arthropods from Australian rainforest canopies: General introduction, methods, sites, and ordinal results. Australian Journal of Ecology 1993, 8:181-191.

Burgstahler,S. Application ofUniversal Design to a Science Lab. DO-IT, University of Washington,2009. www.washington.edu/doit;(Dec 24, 2013)

Gathright, J, Y. Yamada and M. Morita. Tree-assisted therapy: therapeutic and societal benefits from purpose-specific technical recreational treeclimbing programs. Arboriculture \& Urban Forestry2008, 34:222-229.

Haefke, B.J., A.I. Spiers,W.R. Miller and M.D. Lowman. Tardigrades in the Canopy: Using DRT (Double Rope Technique) to conduct vertical transect sampling. Transactions of the Kansas Academy of Science, 2013,116(3/4):119-124.

Kinchin, I.M. The Biology of Tardigrades. Portland Press, London, 1994, pp. 186.

Lowman, M.D. Rain forest insects and their host plants. Biology in Action. 1983.

Lowman, M.D. Temporal and spatial variability in insect grazing of the canopies of five Australian rain forest tree species. Australian Journal of Ecology1985, 10:7-24.

Lowman, M.D. Life in the Treetops. Yale University Press, 1999.

Lowman, M.D. and J.D. Box.Variation in leaf toughness and phenolic content among five species of Australian rain forest trees. Australian Journal of Ecology, 1983, 8:17-25.

Lowman, M.D. and H.E. Heatwole. Spatial and temporal variability in defoliation of Australian eucalypts and its consequence for the dieback syndrome.Ecology, 1982, 73(1):129-142.

Lowman, M.D.and H.B. Rinker. (eds.) Forest Canopies. Elsevier Academic Press, 2004.

Lowman, M.D.,T.D. Schowalter and J.F. Franklin. Methods in Forest Canopy Research. University of California Press, Berkeley,2012, pp. 221.

Laurance, W.F., D.C. Useche, S.G. Laureance and J.A. Bradshaw. Predicting Publication Success for Biologists. Bioscience, 2013, 63(10):817823. 
Miller, WR. Tardigrades: Bears of the Moss. The Kansas School Naturalist, 1997, 43:1-16.

Miller, WR. Tardigrades: Moss Bears in the Canopy. In: Forest Canopies Academic Press,2004, pp. 251-258.

Miller, WR, L. Gallardo L and T. Clark.Chapter 30. Do Water Bears Climb Trees Too? In: Tree Tops at Risk: the Challenges of Global Canopy Ecology and Conservation. Springer, New York, 2013, pp. 307-312.

Miller ,WR, M.D. Lowman and E. McCord. Chapter 33. In the Canopy with Wheelchairs: A Model for Teaching Field Ecology. In: Tree Tops at Risk: the Challenges of Global Canopy Ecology and Conservation. Springer, New York, 2013, pp. 331-339.

Mitchell, C.,W.R. Miller and B. Davis. Tardigrades of North America: Influence of Substrate on Habitat Selection. Journal of the Pennsylvania Academy of Science, 2009, 83(1):10-16.

NSF. Women, Minorities, and Persons with Disabilities in Science and Engineering, 2009, pp. 284.

Preisser, E., M.D. Lowman and D. Smith.Canopy and ground level insect distribution in a temperate forest. Selbyana, 1999, 19(2):141-146.

Ramazzotti ,G.and W. Maucci. Il Philum Tardigrada (third Edition) Memorie dell'Istituto Italiano di Idrobiologia Marco Marchi, 1983, 41, pp.1-1012.

Shaw, D.C., K.A. Ernest, H.B. Rinker andM.D. Lowman.Stand-level herbivory in an old-growth conifer forest canopy. Western North American Naturalist, 2006,66(4):473-481.

Spiers, A.I., B.J. Haefke, W.R. Miller ,and M.D. Lowman.Tardigrades in the Canopy: Doryphoribius dawkinsi Michalczyk and Kaczmarek, 2010- New records from eastern Kansas, U.S.A. Transactions of the Kansas Academy of Science, 2013, 116(3/4):125-128.

Tripp, R.L. In My Nature. Ability Magazine, 2013. 12:50-51.

Wilson, E.O. The Future of Life. Harvard University Press, 2005. 

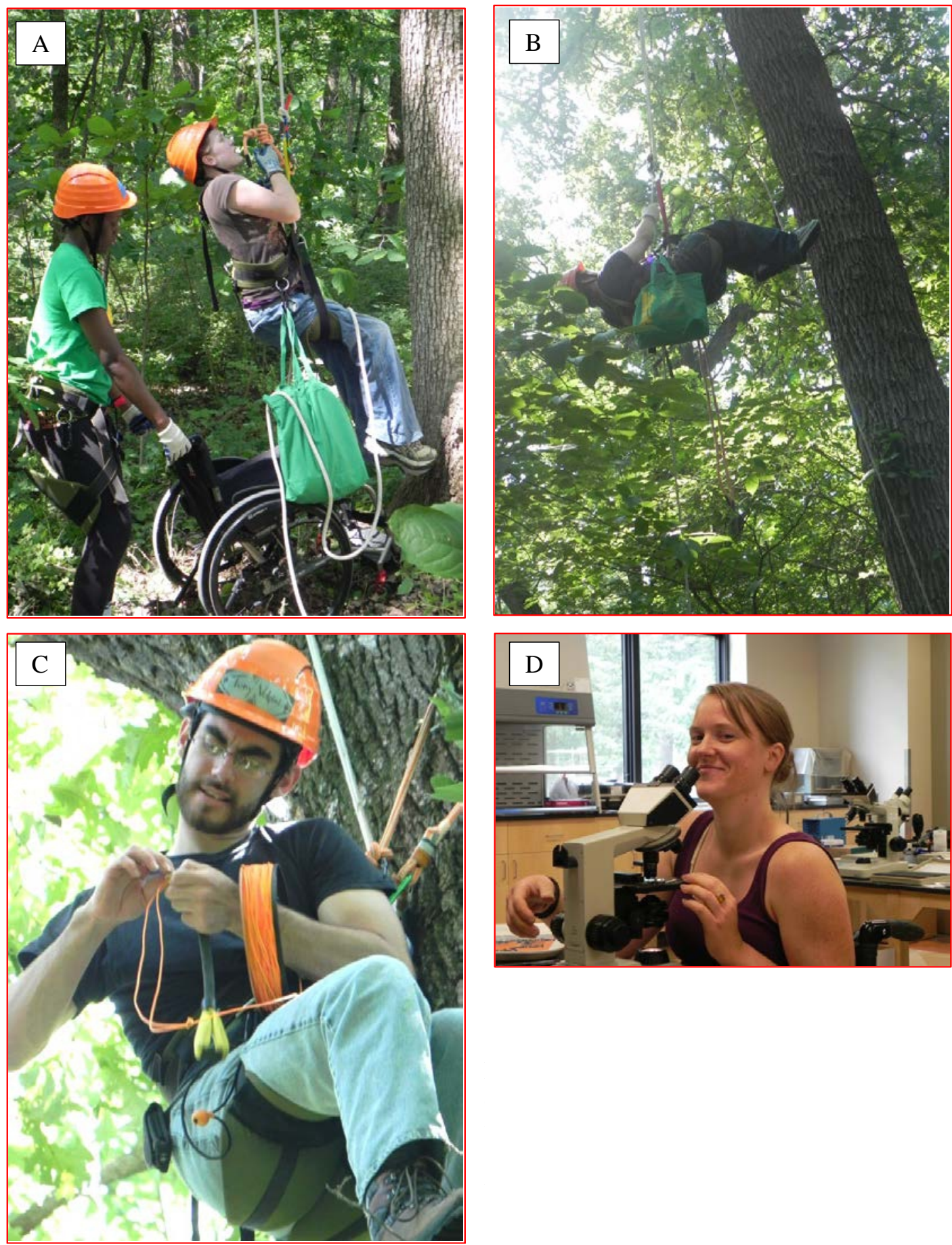

Figure 1. A. Rebecca Tripp lifting out of her wheelchair, B. Devan Glenny ascending into canopy to collect, C. Tony Volpini preparing to sample at 20 meters, D. Rebecca searching her samples for tardigrades. Photographs by W. R. Miller. 


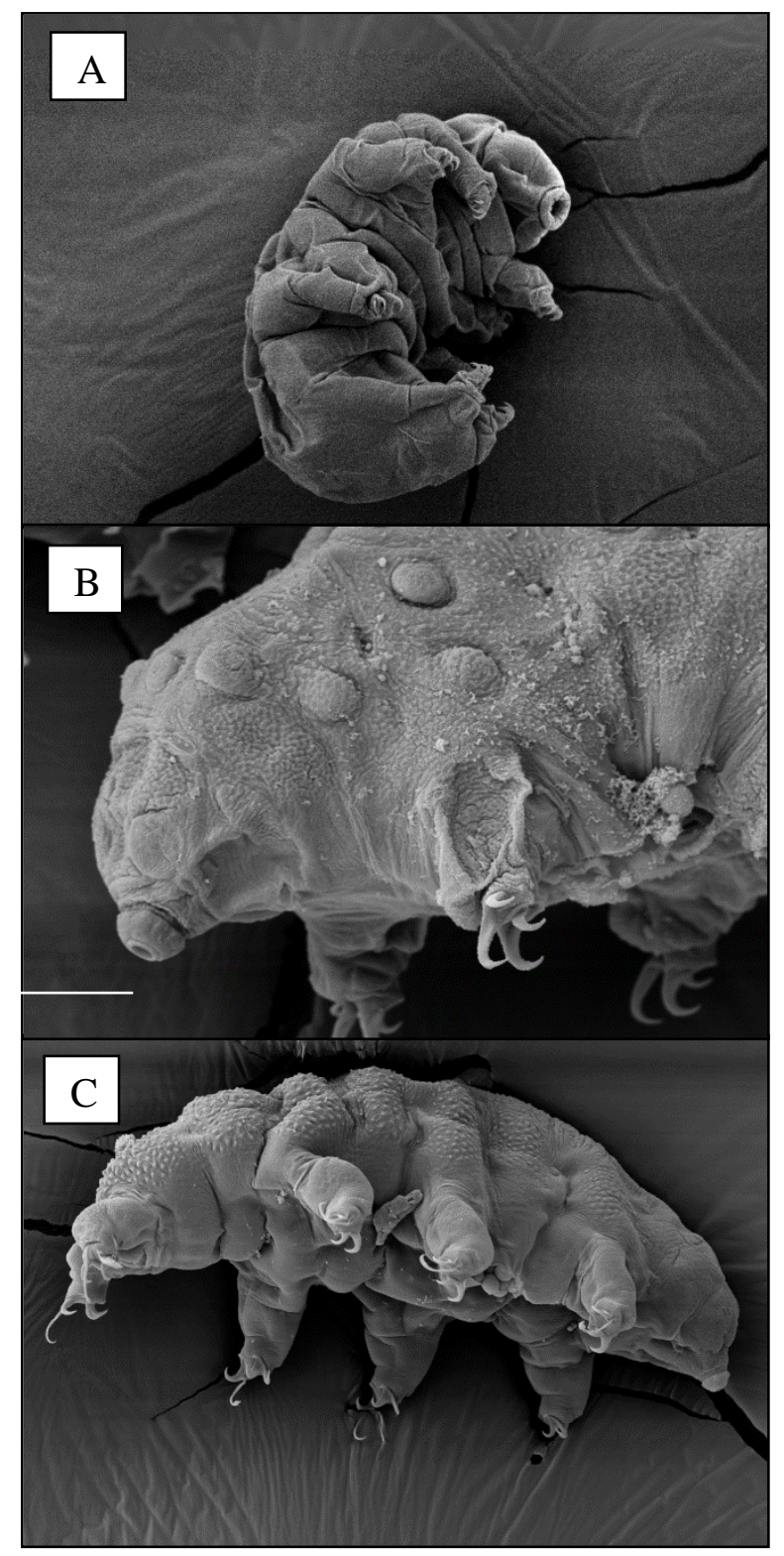

Figure 2. Some tardigrades found.
A. Minibiotus sp., B. Doryphoribius sp.,

C. Ramazzottius sp. Scale bars $=50 \mu \mathrm{m}$. 


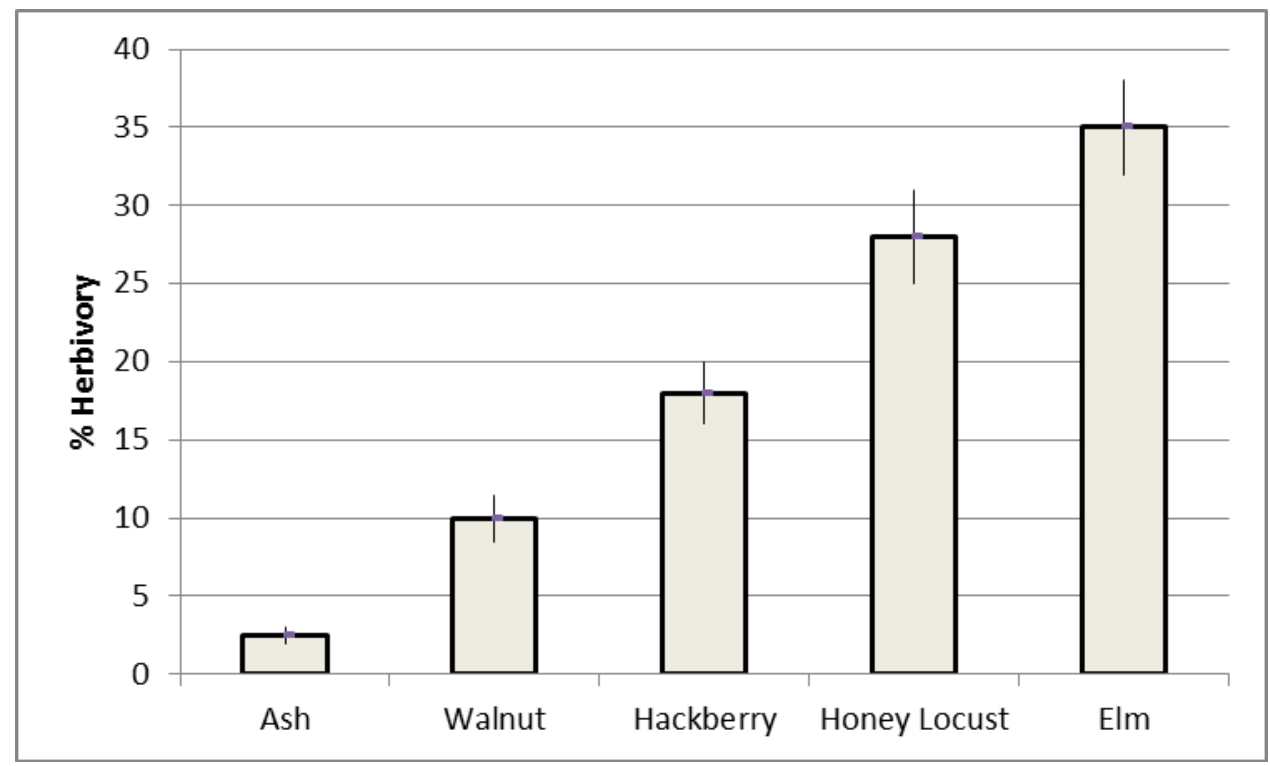

Figure 3. Preliminary indication of differential herbivory by tree species at University of Kansas Field Station site. 
Table 1. Preliminary indication of stratification with more tardigrades found per sample at greater heights into the canopy at eight of ninesites. BU = Baker University, $\mathrm{KU}=$ University of Kansas, and OP = Overland Park.

\begin{tabular}{|c|c|c|c|c|c|c|c|c|c|c|}
\hline 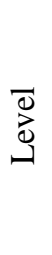 & 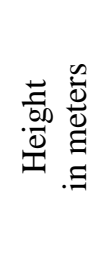 & 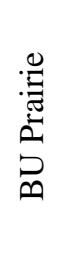 & 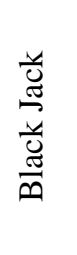 & 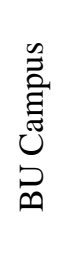 & $\begin{array}{l}n \\
0 \\
0 \\
3 \\
0 \\
0\end{array}$ & 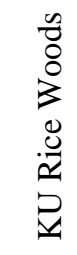 & 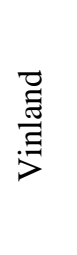 & 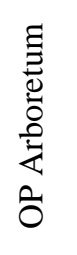 & 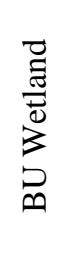 & 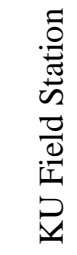 \\
\hline 4 & $>10$ & 30.5 & 4.0 & 13.3 & 11.0 & 10.5 & 8.4 & 6.8 & 19.1 & 10.1 \\
\hline 3 & $7-10$ & 12.7 & 5.0 & 8.3 & 6.5 & 11.3 & 3.4 & 10.8 & 6.1 & 10.0 \\
\hline 2 & $3-7$ & 12.4 & 5.4 & 6.8 & 6.7 & 5.3 & 2.0 & 4.3 & 5.4 & 8.6 \\
\hline 1 & $0-3$ & 7.3 & 10.3 & 9.4 & 3.8 & 0.9 & 6.0 & 3.2 & 2.9 & 6.2 \\
\hline
\end{tabular}

